\section{TUBERCULOSIS IN GERMANY.}

By E. G. Glover, M.D. GlasG., FORMERLY MEDICAL SOPERINTENDENT, BIRMINGHAM MONICIPAL SANATORIUM, CHELTENHAM.

From time to time conflicting newspaper reports reach England as to the exact degree in which Germany bas suffered in well-being as the result of the war, and, for this reason, it is perhaps worth while examining the statistical evidence with reference to tuberculosis. The figures given here are taken from the records of the Gesundheitsamt. Tables A and B are concerned Annual Death-rate from Tuberculosis of All Organs per 10,000 Liting Inhabitants.

\begin{tabular}{|c|c|c|c|c|c|c|}
\hline \multicolumn{3}{|c|}{ A.-Whole of Prussia. } & \multicolumn{4}{|c|}{ B.-In German towns. } \\
\hline Year. & $\begin{array}{c}\text { Absolute } \\
\text { No. }\end{array}$ & $\begin{array}{l}\text { Death- } \\
\text { rate. }\end{array}$ & Yéar. & $\begin{array}{c}\text { No. of } \\
\text { districts. }\end{array}$ & $\begin{array}{l}\text { Absolute No. } \\
\text { (civil and } \\
\text { military). }\end{array}$ & $\begin{array}{l}\text { Death- } \\
\text { rate. }\end{array}$ \\
\hline 1892 & - & $26^{\circ} 0$ & 1914 & 386 & 41,730 & $16^{\circ} 0$ \\
\hline 1913 & 56,861 & $13^{\circ} 6$ & 1915 & 383 & 44,805 & $16 \cdot 8$ \\
\hline 1914 & 58,577 & $13 \cdot 8$ & 1916 & 383 & 48,779 & $18^{\circ} 0$ \\
\hline 1915 & 61,606 & $14 \%$ & 1917 & 383 & 67,860 & $25^{\circ} 2$ \\
\hline 1916 & 66,544 & $15^{\circ} 7$ & 1918 & 373 & 75,160 & $28 \cdot 7$ \\
\hline 1917 & 87,032 & $20^{\circ} 5$ & 1919 & 365 & 66,604 & 271 \\
\hline 1918 & 96,844 & $22 \cdot 8$ & & & & \\
\hline
\end{tabular}

merely with the death-rate from tuberculosis, since there is no compulsory notification of infection in Germany, but only a compulsory notification of deaths from tuberculosis.

The figures in Table A are for the whole of Prussia, town and country included; in round figures, we may note specially the fall of the death-rate from 26 in 1892 to 13.8 in 1914 and the rise to 22.8 in 1918 . As, however, the figures for rural districts always water down the tuberculosis death-rate it is advisable to consider the town death-rate as given in Table B. In this case the figures are for the whole of Germany and deal with the rate in towns of 15,000 inhabitants and over in about 380 districts, the population concerned totalling $25,797,000$. The increase from 1914 is again remarkable, and we may say that between 1914 and 1919 100,000 more patients died than might have been expected, calculating from the rates of 1914. These figures are perhaps less illuminating as there is no record for Alsace-Lorraine in 1918-19, and none for Posen in 1919, and over 10.000 other fatal cases have, therefore, not been included.

Owing to the faulty system of notification in Germany, and the frequent lack of differentiation between lung tuberculosis and tuberculosis of all organs, it is difficult to give satisfactory figures with regard to lung disease, but a rough idea may be obtained from Table $\mathrm{C}$, which deals with lung rates in some towns, districts, and and provinces.

TABLE C.-Death-rate of Lung Tuberculosis per 10,000 Living.

\begin{tabular}{lll|c|c|c|c|c}
\multicolumn{2}{r|}{ Place. } & & 1885 & 1913 & 1917 & 1918 & 1919 \\
\hline Berlin ... & $\ldots$ & $\ldots$ & $34^{\circ} 6$ & $16^{\circ} 6$ & $30^{\circ} 4$ & $29^{\circ} 9$ & $23^{\circ} 3$ \\
Hessen & $\ldots$ & $\ldots$ & $29^{\circ} 2$ & $12^{\circ} 5$ & $21^{\circ} 2$ & $20^{\circ} 0$ & $19^{\circ} 0$ \\
Bavaria & $\ldots$ & $\ldots$ & $25^{\circ} 4$ & $14^{\circ} 7$ & $17^{\circ} 0$ & $17^{\circ} 6$ & - \\
Prussia & $\ldots$ & $\ldots$ & - & $12^{\circ} 0$ & $18^{\circ} 2$ & $20^{\circ} 5$ & - \\
Munich & $\ldots$ & $\ldots$ & - & $17^{\circ} 3$ & $21^{\circ} 9$ & $23^{\circ} 9$ & - \\
Saxony & $\ldots$ & $\ldots$ & $25^{\circ} 0$ & $11^{\circ} 4$ & $13^{\circ} 1$ & $\begin{array}{c}\text { Incom- } \\
\text { plete. }\end{array}$ & - \\
\end{tabular}

The difference between industrial and rural areas in Table C. is very striking, With regard to the increase in the tuberculosis "infection-rate" this can only be guessed in Germany, but going on the assumption that at least twice the total number of deaths represents the number of cases living (and this, in England at any rate, would be a very modest assumption), we may take it that in 1913 there were 200,000 cases, and that in 1918 this figure had risen to 340,000 . As a matter of fact, the Gesundheitsamt estimates that there are at present little short of 500,000 cases in Germany, and this is probably true.

A certain amount of corroborative evidence can be had from general health statistics, although naturally less stress can be laid on their probable accuracy. From a report of the Reichs-Versicherung one finds that whereas in 191310,400 adults were on the sick-list, in 1919 this number had risen to 43,000 ; in Hamburg the number of tuberculous patients receiving extra nourishment rose to nearly double in the period from November, 1917, to August, 1919; in Berlin the death-rate for women and children rose from 14 in 1913 to 19 in 1920 (this last figure making due allowance for the influenza epidemic). According to the Berlin Industrial Friendly Society the percentage of deaths caused by tuberculosis, in relation to the total deaths from all causes, is as follows:-

\begin{tabular}{ccccccccc} 
& & \multicolumn{4}{c}{ Men. } & \multicolumn{3}{c}{ Women } \\
1914 & $\ldots$ & $\ldots$ & $\ldots$ & $\ldots$ & $\ldots$ & 30 & $\ldots \ldots \ldots .$. & 32 \\
1917 & $\ldots$ & $\ldots$ & $\ldots$ & $\ldots$ & $\ldots$ & 42 & $\ldots \ldots \ldots \ldots$. & 45 \\
1919 & $\ldots$ & $\ldots$ & $\ldots$ & $\ldots$ & $\ldots$ & 35 & $\ldots \ldots \ldots \ldots$. & 39
\end{tabular}

As is well known, a similar rise in tuberculosis deathrates and morbidity-rates occurred in England during the war (speaking from memory, the number of actual deaths in England and Wales rose from 49,000 in 1913 to 58,000 in 1918), but compared with the rates in 1892 it is not nearly so striking as in Germany. The figures before 1892 in Germany are not very reliable or rather not comparable. It is therefore interesting to inquire whether in Germany, as in England, an improvement took place after the conclusion of hostilities. That such an improvement did take place can be gathered from the following figures, which show the half-yearly deathrates per $10,000:-$

\begin{tabular}{lllllll} 
& \multicolumn{4}{c}{ First half. } & \multicolumn{2}{c}{ Second half. } \\
$1914 \ldots$ & $\ldots$ & $\ldots$ & $\ldots$ & $17 \cdot 5$ & $\ldots \ldots \ldots$ & $14 \cdot 6$ \\
$1919 \ldots$ & $\ldots$ & $\ldots$ & $\ldots$ & $34 \cdot 4$ & $\ldots \ldots \ldots$ & $27 \cdot 1$ \\
$1920 \ldots$ & $\ldots$ & $\ldots$ & $\ldots$ & $25 \cdot 6$ & $\ldots \ldots \ldots$ & (?) 16 (incomplete).
\end{tabular}

All the figures go to show that the highest death-rate was reached in 1918, and that, especially in the second half of 1919 , there was a marked improvement which has since continued. The same applies to the statistics for living cases. The figures for the Berlin Kranken. kasse show a distinct drop since 1918, and this is confirmed by the Stettin report, but it is interesting to note that in Mannheim (where industrial conditions are very bad) the reverse holds true, especially for infectious patients. Not only has the rate risen there, but whereas in 1918 of all new cases 17 per cent. were infectious, in 191921 per cent. were infectious. Whether the rates will shortly fall to the pre-war level is an open question, but taking into account the present food situation in Germany it seems unlikely. As a rough approximation one might say that the present food conditions in Germany are much worse than they were ever in England at the worst time of the war, and that this must affect the next ten years at least, especially amongst those who are at present in youth or adolescence.

\section{Methods of Fighting Tuberculosis.}

On the other hand, the fact has to be faced that the present organisation of antituberculosis work in Germany is unable to cope with the problem: firstly, because of lack of money; secondly, because the German is no longer as docile and amenable to health regulations, or, indeed, to any official regulations, as formerly; and thirdly, because the dispensary system has not been effectively organised, especially with regard to treatment and after-treatment. Of course, there are many excellently organised centres, as in Stettin, but in other places these are absent, and in large towns like Berlin there are so many organisations that within a circle of stools the unfortunate patient falls to the ground. The working of the insurance regulations in a town like Berlin is curious. Sick benefit is organised and administered, as in England, through the medium of the Krankenkassen, but tuberculosis work is in the hands of the invalidity department. This is due to the fact that since the invalidity section suffered so much from tuberculosis unemploy- 
ability they set out, at first, to attempt to cure tuberculous cases; and latterly, to attempt to prevent infection. For this reason the Landes-Versicherung has a well-organised system of dispensaries, sanatoriums, \&c.

The uninsured are less fortunate. True, at the Charité (a model University hospital) there exists an organisation where officials of the more needy class, small shopkeepers, shop assistants, and widows and children without means can receive treatment. In 1919,6080 were on the books, and in 1920 this rose to 9200. As a side-light on present conditions, it may be noted that in 1919 the figure included 38 authors and artists, a few doctors and lawyers, and several hundred Government officials, many of whom were of high grade. At the Charité the patient pays one-third of his own costs, the employers, if any, are approached to pay another third, and the remainder is found from various sources - e.g., the municipality, the Government, the Deutsche Central-Komitee, or privately.

An additional complication in Berlin was introduced by the extension of the town boundaries. In the suburbs, both rich and poor, regional dispensaries existed for dealing with the diagnosis and home visitation of tuberculosis cases, and these have not yet been absorbed into any central organisation. Both insured and uninsured are dealt with here, and here, as with the Landes-Versicherung and Charité, the families of infected cases are dealt with. It is expected that in the near future this family system will apply to diseases other than tuberculosis. In practice, then, a tuberculous patient is recommended by his private doctor, or by the Kassenarzt (insurance doctor) or by his Poor-law doctor (Armenarzt) to go, or goes of his own initiative, to a local Fürsorgestelle (dispensary), whence, if insured, he is transferred to the Insurance Organisation, or where, if uninsured, various attempts are made to provide him with treatment.

Deficiencies of the System.

But when one comes to inquire what this treatment actually amounts to, the German system, sometimes through no fault of its own, shows up very badly. In all Germany in the year 1918-1919 there were 168 sanatoriums, with 17,500 beds, and for children 172 institutions, with 14,000 beds. This does not include, of course, a number of beds in the various hospitals and Poor-law infirmaries. In Berlin, for example, there are 378 beds in hospitals and 160 in Poor-law infirmaries, mainly for hopeless cases, leaving roughly about 680 available beds in proper tuberculosis sanatoriums. This, for a population of over four million under present conditions of infection, is much too little. It is estimated at the Gesundheitsamt that only 25 per cent. of any new series of cases can get effective sanatorium treatment; the Charite authorities estimate the figure at 35 per cent., and it is at any rate safe to say that 50 per cent. do not get adequate treatment. The period of treatment, too, has been reduced, largely through lack of money, to 6-8-10 weeks' duration. Moreover, it is much more difficult for uninsured cases to obtain treatment; the uninsured Fürsorge-Stellen must go from pillar to post begging or purchasing sanatorium accommodation under various organisations in various parts of the province of Brandenburg.

This deficiency in sanatorium treatment would not be serious if at the various dispensaries there was provided effective out-patient treatment or after-treatment. Unfortunately this is not so. The dispensaries are exceedingly well organised as far as diagnosis, statistical records, the supply of printed forms, innumerable recommendation forms, and the dispensing of good advice is concerned; they are also the centre-point for a staff of efficient nurse-supervisors, but the dispensing of medical treatment is practically unknown. There are, indeed, many insurance dispensaries where tuberculin is administered, and the Charité in Berlin has a fairly efficient treatment clinic for uninsured cases, but in general there is no treatment in dispensaries. The patient has the cold comfort of accurate diagnosis, and must thereafter extract what satisfaction he can from printed recommendations. What the dispensaries have done in the past and still try to do is to distribute food, cod-liver oil, and clothing to needy cases, but at the present time this is practically a dead letter. When the tuberculosis patient in Germany asks for bread he is almost literally given a stone, or at least a bread. substitute which closely resembles emery-paper.

In practice, treatment is limited (if one exclude the small amount of sanatorium treatment provided) to home-care, or, as it is euphemistically termed in England, "domiciliary" treatment. This is usually carried out by the Insurance or private doctor. The Poor-law doctor also treats cases, but he is not in great demand; the Brandenburger hates the Poor-law and, indeed, until recently at any rate, treatment by Poor-law officials entailed loss of certain civil rights. The end of the tuberculosis story in Germany is very simple: notification of the patient's death is made under legal statute to the Kreisarzt who is really the police doctor, the house is sterilised, the children are examined, and that is the end.

\section{Some Observations.}

Three observations of some interest may be made. Amongst all classes in Germany the relatively alarming increase in tuberculosis is attributed mainly to the effect of the "Hunger-blockade" as it is called, and by the same classes it is held that improvement in tuberculosis is greatly retarded by the transfer to other countries of a large proportion of milk cows. On the other hand, some tuberculosis authorities are, all things considered, very optimistic about the future of the tuberculosis crusade and think that in a comparatively short time after food-supplies approximate to the normal quantity the rates will also fall to normal. The outside observer, remarking as he must, the lean, yellow, under-nourished look of German youths cannot but feel that this bodes ill for the tuberculosis rate in ten or so years' time, and finds such optimism is premature.

The second observation is that England and America have every reason to feel proud of the activities of the various relief missions, especially those of the Quakers, who unobtrusively, but effectively, help in some way to provide children, apprentices, university students (and in the near future, it is hoped, tuberculous cases) with adequate nourishment. It is true that often only the fringe of the problem is touched, still the attempt is one which deserves all praise.

The last observation is that the average German appears to have only a theoretical acquaintance with the principles of fresh-air inhalation; preferably he takes his air well boiled, or at any rate half cooked; real fresh air he relegates to its natural habitatviz., out of doors. It is worthy of comment that the interior of many tuberculosis institutions is warm enough to make the enthusiastic foreigner mop his inquisitive brow, and to make him sigh for the English system whereby he no sooner enters a tuberculosis centre than he is almost blown out of the exit. In Germany, however, this does not apply to the poorer institutions and not to the homes of the poor. It should be remembered that even substitute coal in Germany costs more marks than the indigent can afford.

I am obliged to Professors Möllers and Kayserling, to Dr. Helm, to Geheimrat Pütter, and many others for much information and the privilege of inspecting their institutions and statistics.

Berlin, Feb. 8th, 1921

Serbian Workers Reunion.-The second annual reunion of the workers for Serbia will be held at the Wharncliffe Rooms, Great Central Hotel, London, on Tuesday, April 19th. Colonel Sir Courtauld Thomson, Chief Commissioner of the British Red Cross in the Near East from 1915 to 1919 , will take the chair. Dinner 7 for 7.30 P.M. dancing at 9.30 P.M. Last year 164 were present, and it is hoped that all medical men and women who served with the medical missions or with the R.A.M.C. units attached to the Royal Serbian army will attend. Application for tickets should be made before April 12th to the honorary secretary, Miss Marx, 24, Melcombe-court, Dorset-square, London, N.W.1. 